\title{
Some Chemical Carcinogens for Leukaemia Induction and Their Animal Models
}

\author{
Abdullahi Aliyu ${ }^{1,2^{*}}$, Mohd Rosly Shaari ${ }^{3}$, Noordin Mohamed Mustapha ${ }^{1}$, \\ Nurul Syahirah Ahmad Sayuti ${ }^{1}$, Mohd Farhan Hanif Reduan ${ }^{1}$, \\ Shanmugavelu Sithambaram ${ }^{3}$, Khozirah Shaari $^{4}$ and Hazilawati Hamzah ${ }^{1^{* *}}$ \\ ${ }^{1}$ Department of Veterinary Pathology and Microbiology, Faculty of Veterinary Medicine, \\ Universiti Putra Malaysia, 43400 UPM, Serdang, Selangor, Malaysia. \\ ${ }^{2}$ Department of Veterinary Pathology, Usmanu Danfodiyo University, Sokoto, Nigeria. \\ ${ }^{3}$ Animal Science Research Centre, Malaysian Agricultural Research and Development Institute, \\ Headquarter, 43400, Serdang, Selangor, Malaysia. \\ ${ }^{4}$ Department of Chemistry, Faculty of Science, Universiti Putra Malaysia, Selangor 43400, Malaysia.
}

Authors' contributions

This work was carried out in collaboration among all authors. Authors AA, NMM, SS, KS and HH designed the study. Authors AA, MRS and HH wrote the first draft of the manuscript. Authors AA, NSAS and HH managed the analyses of the study. Authors AA, MRS, MFHR and HH managed the literature searches. All authors read and approved the final manuscript. Article Information
DOI: 10.9734/ARRB/2019/v33i130108
Editor(s):
(1) Prof. Ibrahim Farah, Professor, Jackson State University, Mississippi, USA.
Reviewers:
(1) David Akinbo, Afe Babalola University, Nigeria.
(2) Heba Gamal Abd El-Aziz Nasr, Al-Azhar University, Egypt.
Complete Peer review History: http://www.sdiarticle3.com/review-history/50887

Review Article

Received 19 June 2019

Accepted 23 August 2019 Published 09 September 2019

\begin{abstract}
Animal models have been providing invaluable contributions to the better understanding of mechanisms of cancer (including leukaemias) development and effectiveness of most of the treatments. Chemical carcinogens are generally used to study the biology of cancers including leukaemias in many animal models, including rats and mice. The studies in most cases are aimed at the development and evaluation of cancer treatments and preventions. Some of the most common chemical carcinogens used in animal models for leukaemias include $N$-ethyl- $N$ nitrosourea (ENU), $N$-methyl- $N$-nitrosourea (MNU), dimethyl benz(a)anthracene (DMBA) and benzo(a)pyrene (BaP). This review provides highlights on different animal models of leukaemia
\end{abstract}


induced by the chemical carcinogens mentioned earlier, at the same time discussing the contributions of these models to the leukaemia diagnosis in laboratory animal models for subsequent development of treatment.

Keywords: Animal model; Dimethyl Benzanthracene (DMBA); Benzo (a) pyrene (BaP); Leukaemia, Nethyl-N-nitrosourea (ENU); N-methyl-N-nitrosourea (MNU).

\section{INTRODUCTION}

Leukaemia refers to the neoplastic proliferation of lymphoid and myeloid progenitor cells as a result of the mutation of a single stem cell, the progeny of which form a clone of leukaemic cells. Leukaemia is broadly classified into acute and chronic leukaemias, each of these is further subdivided into myeloid and lymphoid; i.e. acute myeloid leukaemia, acute lymphocytic leukaemia, chronic myeloid leukaemia, and chronic lymphocytic leukaemia [1]. It has been reported that CLL is the most common type of leukaemia found, however, AML accounts for about $42 \%$ of all leukaemia deaths [2]. The causes of leukaemia are not well understood; however, alkylating drugs, ionizing radiation, and chemicals have been incriminated. These factors have been shown to induce chromosomal abnormalities resulting in DNA changes. [3] reported leukaemia to be the most common type of cancer developed following treatment with alkylating agents, predominantly nonlymphoid leukaemia.

Various animal models have been developed to investigate the factors involved in malignant transformation, invasion and metastasis, at the same time to investigate the effectiveness of the treatment (therapy). The importance of animal models on cancer research; leukaemia inclusive cannot be overemphasized. These include studies on oncogenesis, molecular genetics, microenvironment, metastasis, therapeutic effects, etc. [4]. Biochemical researches are primarily designed to provide advanced knowledge which could be used to predict disease pathology and pathophysiology by a clinician and at the same time to choose the appropriate treatment. Animal models can be used to test relationships and mechanisms under controlled experimental conditions which can be used to predict clinical outcomes in humans [4]. Animal models can also assist in identifying the exogenous agents to which the exposure may underlie leukaemic induction. Chemically induced leukaemic animal models are generally used to study the pathogenesis of leukaemia to develop the treatment and prevention of cancer [5].

This review focused on chemical carcinogens used in different animal models to understand the mechanisms of cancer development and the effectiveness of some of the treatments tested.

The most commonly used chemical carcinogens in studying the progression of leukaemia are $\mathrm{N}$ ethyl- $N$-nitrosourea (ENU), $\quad N$-methyl- $N$ nitrosourea (MNU), dimethyl benzanthracene (DMBA), benzo (a) pyrene (BaP), amongst others. This review will focus on these chemicals as they are commonly used in rat and mouse models.

\section{METHODOLOGY}

\subsection{Nitrosoureas}

Nitrosoureas (ENU, MNU, etc.) were extensively used in the treatment of cancers in the past. They spontaneously decompose to generate two reactive species; namely, an alkylating group and a carbamoxylating group, either of these products may react with DNA, RNA or protein, thereby causing serious and often prolonged bone marrow suppression [6]. The mechanism of action of nitrosoureas involved transfer of its alkyl (ethyl or methyl) group to the nucleobases of the cancer cells, this causes DNA changes. The transfer of the alkyl group requires the action of an enzyme; alkyl transferase from the bone marrow, this causes the decreased concentration of the enzymes within the bone marrow, leading to leukaemogenesis [7]. Alkylation of DNA occurs relatively homogeneously throughout the body due to the non-enzymatic formation of the reaction product. This is like most chemotherapy drugs. which generally cause DNA damage without cytochrome p450-mediated bioactivation. If a methyl or ethyl adduct is not removed by alkylguanine transferase, the whole nuclear base adduct may be removed via 
excision repair. Removal of the modified base and neighbouring nucleotides creates a strand break, which causes the activation of the nuclear enzyme, poly(ADP-ribose) polymerase (PARP). Activated PARP makes use of NAD+ as a substrate in the synthesis of poly(ADP-ribose). It is usually the main acceptor protein, however a number of other nuclear proteins became modified to some extent [8]. The concentration of negatively charged poly(ADP-ribose) at the site of DNA damage may play several roles, including regulation of excision repair, p53 function and apoptosis [9]. The most consistent evidence, however, shows that poly(ADPribose) synthesis prevents recombination events at the site of damage, perhaps by repelling other DNA strands, thereby decreasing the risk of chromosomal translocations. This is critical in the bone marrow because the majority of leukaemias resulted from translocation events of this nature [9].

\subsection{Leukaemia Induced by $\mathrm{N}$-Ethyl- $\mathrm{N}$ - Nitrosourea (ENU)}

Ethyl nitrosourea is a monofunctional ethylating agent that has been used as a simple model of chemotherapeutic nitrosoureas. Monofunctional nitrosoureas are potent leukaemogenesis that model the leukemogenic aspect of chemotherapeutic agents quite well, especially when used in certain strains of rats such as Long Evans, which respond with primarily nonlymphocytic leukaemias. The leukaemic effects of ENU have been reported in both mice and rats. A leukaemic induction protocol using intravenous injection in rats was previously reported. Two different groups of rats; groups A and $B$ were given intravenous (IV) injection of $225 \mathrm{mg} / \mathrm{kg}$ total dose of ENU. Group A, which comprises of 2003 -months old male Wistar rats, were administered $15 \mathrm{mg} / \mathrm{kg}$ ENU weekly IV for 15 weeks, while group B comprising the same number of animals at the same age received the same total dose of $225 \mathrm{mg} / \mathrm{kg}$ ENU by IV injection of $75 \mathrm{mg} / \mathrm{kg}$ ENU weekly for three weeks. After the last dose of ENU in each of the two groups, liver and spleens were palpated on weekly basis; any rats with splenomegaly and /or hepatomegaly were subjected further to complete blood count, peripheral blood smears and later liver biopsy to confirm the presence of leukaemia [10].

In group A, leukaemia was observed in $91(45.5 \%)$ of the total animals; among these 76
(83.5\%) were acute leukaemias diagnosed at 37 weeks whereas $15 \quad(16.4 \%)$ were chronic myeloid leukaemias which occurred at 30 weeks. However, group $B$, on the other hand, presented $63(31.5 \%)$ total leukaemias, where $57 \quad(90.5 \%)$ were acute with minimum manifestation time of 35 weeks and $6(9.5 \%)$ were chronic myeloid leukaemias with a minimum manifestation of 33 weeks [10].

The leukaemia presented by the rat was characterized in addition to an enlarged spleen, liver and lymph nodes, by various sizes and shapes of blast cells from the peripheral blood. The cells had round or oval nuclei with occasional indentations containing 13 nucleoli. Moreover, the cytoplasm of the cells had no azurophilic or neutrophilic granules [10].

In another study, lymphoblastic leukaemia was predominantly reported in 5-10 days old albino mice injected with ENU at a dose rate of 80 $\mathrm{mg} / \mathrm{kg}$ intraperitoneally (IP) within 4-7 months post-inoculation [11]. Out of the total experimental animals, $15 \%$ died due to acute toxicity within 2-3 days after injection, $25 \%$ died from secondary infections and $60 \%$ presented a progressive leukaemia status, characterized by leukaemic blasts cells in both the bone marrow and peripheral blood smears [11].

The effect of IP administration of $80 \mathrm{mg} / \mathrm{kg}$ twice at a one-week interval in 7-10 days old BALB $c$ male mice were also studied. Leukaemia was confirmed 5 months after the last ENU injection by the appearance of numerous blast cells in peripheral blood and bone marrow smears. Leucocytosis was also observed in the challenged group compared to the untreated animal. However, 2 of the 12 experimental animals died acutely [12].

Subsequently, [13] studied the effect of IP injection of ENU on older mice. Three weeks old $\mathrm{BALB} / \mathrm{c}$ mice were administered $80 \mathrm{mg} / \mathrm{kg}$ ENU IP twice at a one-week interval. In this case, five months post-injection of the chemical, leukaemia was established, characterized by the appearance of undifferentiated blast cells in the blood and bone marrow smears, however, no mortality was reported [13]. Perhaps due to the age of the experimental animals in the study. 


\subsection{Leukaemia Induced by $N$-Methyl- $N$ - Nitrosourea (MNU)}

The carcinogenic potential of MNU in Wistar rat was reported previously. It was demonstrated that MNU promptly promotes malignant lymphoma and leukaemia [14]. Three weeks old male Wistar rats weighing 220-230 g were grouped into 4 groups; group A served as the control, while groups $\mathrm{B}, \mathrm{C}$ and $\mathrm{D}$ were respectively administered $20 \mathrm{mg} / \mathrm{kg}$ of body weight (total of $80 \mathrm{mg} / \mathrm{kg}$ ), $40 \mathrm{mg} / \mathrm{kg}$ of body weight (total of $160 \mathrm{mg} / \mathrm{kg}$ ) and $60 \mathrm{mg} / \mathrm{kg}$ of body weight (total of $240 \mathrm{mg} / \mathrm{kg}$ ) MNU, intraperitoneally. A total of four injections (two injections per week) were administered during the first two weeks of the experiments. The animals were then closely observed and sacrificed at the $12^{\text {th }}$ and $20^{\text {th }}$ weeks, where specific organs including thymus, spleen, bone marrow, cervical and mesenteric lymph nodes and liver were collected for analysis. At the $20^{\text {th }}$ week, lymphohematopoietic system (LHS) malignant tumours and benign vascular tumours occurred only in the high- and intermediate-dose $\mathrm{MNU}$-treated animals. Four animals treated with $240 \mathrm{mg} / \mathrm{kg}$ developed diffuse thymic lymphomas; two others treated respectively with $240 \mathrm{mg} / \mathrm{kg}$ and $160 \mathrm{mg} / \mathrm{kg}$, developed spleen haemangiomas. Animals in group $\mathrm{C}$ demonstrated significant decrease in the mean body weights, at the same time developed a tumour of the thymus and spleen at week 20 of the experiment [14]

Hutheyfa [15] studied the carcinogenic effect of MNU in Sprague Dawley (SD) rats where it was reported that IP injection of MNU twice weekly for two consecutive weeks at 60 $\mathrm{mg} / \mathrm{kg}$ (total dose of $240 \mathrm{mg} / \mathrm{kg}$ body weight) induced stage IV lymphoma characterized by enlargement of the lymph nodes, hepatosplenomegaly (in $30 \%$ of the treated animals) and enlarged kidneys in $7 \%$ of the rats. It was further reported that the organs were infiltrated with malignant lymphocytes in different grades [15].

The effect of intravenous injection of MNU in Sprague Dawley (SD) rats has also been reported. Seven weeks old SD rats were given a series of six IV injections of MNU at $35 \mathrm{mg} / \mathrm{kg}$ body weight biweekly via the caudal vein and observed for a period of 220 days (1). During the period of observation, the animals were individually monitored daily for mortality and weekly for clinical signs and body weight changes. Blood samples were analysed at $30-40$ days intervals after the final dose of MNU for complete blood count with differentials, cytology (smears were prepared for Liu's and Papanicolaou stains) and serum biochemistry. The animals were sacrificed humanely after the $220^{\text {th }}$ day of the experiment. Biopsies of the liver and spleen were prepared for both histopathological and immunohistochemical evaluations.

Leukaemia was observed in $97.1 \%$ of the total animals treated. The treated (leukaemic) group showed less body weight compared to the untreated group with a significant increase in liver and spleen weights. The treated rats also presented a significant leucocytosis with neutropenia, however, the red blood cells (RBC) counts and haemoglobin $(\mathrm{Hb})$ concentration were decreased (which signifies tendency to anaemia). The study suggested that MNU caused leucocytosis without affecting the neutrophil index. The increased production of blast cells led to a reduction in the percentage of normal neutrophils and implied a direct correlation between leukaemia blasts and the number of white blood cells (WBCs) (1). The study reported further that, MNU was able to induce a significant increase in the serum concentration of GOT and GPT, at the same time the uric acid level in the serum of leukaemic rats was found to be higher than the control group. Cytologically, Papanicolaou and Liu's staining techniques were employed for the analysis of the slides. More atypical cells were found in the MNU treated group compared to the control. Papanicolaou staining method revealed round cells that were dark blue in colour and about two to three times the size of lymphocytes. The Liu's stained smears, on the other hand, were cellular and revealed a markedly polymorphous mixture of small to large cells in the leukaemic rats. Liu's stain further revealed a larger proportion of large, dark staining, blast-like promyelocytes and metamyelocytes as well as dysplastic granulocytes (1). Liu's staining method is considered more sensitive in the classification of leukaemia/lymphoma, this is because it differentiates the lymphoblast from myeloblasts more precisely than the Papanicolaou stain (1). Histologically, there was frequent enlargement of liver and spleen in all cases, which also presented leukaemic cellular infiltration on the portal area and sinusoids of the liver. The normal architecture of red and white pulp of the spleen was destroyed in MNU treated rats with a massive spread of undifferentiated leukaemic 
cells. The immunohistochemical analysis revealed that CD3 (which generated an active signal in $\mathrm{T}$ lymphocytes) and CD20 (which is active in all B-cell lymphomas and leukaemia) expression were negative in malignant cells. However, MPO (myeloperoxidase) staining was strongly positive in neoplastic cells, indicating that MNU induced blast cells were derived from the myeloid lineage. This is because MPO stain distinguishes myeloblastic from lymphoblastic leukaemias [16].

\subsection{Leukaemia Induced by DMBA (7, 12 Dimethylbenz[A]Anthracene)}

Dimethylbenz[a]anthracene (DMBA) is an immunosuppressor and considered a powerful organ-specific laboratory carcinogen that is widely used in many cancer researches as a tumour initiator. Leukaemia due to DMBA was studied previously [17], by injecting pulse doses of $45-25 \mathrm{mg} / \mathrm{kg}$ body weight DMBA intravenously via the lateral caudal vein for $5-6$ times at 10-14 days intervals in 27 days old Long Evans rats. The tail was warmed in water of $43^{\circ} \mathrm{C}$ prior to injection to make the vein more prominent for easy injection. The doses were administered in decreasing order of $45,40,35,30,30$ and 25 $\mathrm{mg} / \mathrm{kg}$. This is because the older the animals the less tolerance it becomes to DMBA [18]. Moreover, the anaemia and leucopoenia induced by DMBA made the rats less tolerant to the chemical.

Leukaemia was also reported within 2.5 to 5 months in $47 \%$ of Wistar rat fed $1-2 \mathrm{mg}$ DMBA twice a week. An initial dose of $200 \mathrm{mg} / \mathrm{kg}$ DMBA was administered to Long Evans rats starting from 4-8 weeks of age, this was followed by a set of seven doses of $10 \mathrm{mg} / \mathrm{kg}$ in $2 \mathrm{ml}$ of sesame oil at two weeks intervals. This caused leukaemia in $72 \%$ males, $82 \%$ females and mammary cancer in $20 \%$ males and $66 \%$ females. From this study, it is recommended that feeding of DMBA is a simple procedure for leukaemia induction, as it does not require any technical skills.

\subsection{Benzo(A)Pyrene (BaP) Leukaemia Animal Model}

Benzo(a)pyrene (BaP) is a ubiquitous polycyclic aromatic hydrocarbon that is formed from the incomplete combustion at temperature ranges between $300^{\circ} \mathrm{C}$ to $600^{\circ} \mathrm{C}$. BaP is mainly found in residential wood burning, coal tar, tobacco smoke, automobile exhaust fumes (particularly from diesel engines), and many foods including grilled meats. Its metabolites react and bind to DNA causing mutations and cancer eventually. It is considered as a group 1 carcinogen by the international agency for research on cancer (IARC). It is considered as the most thoroughly investigated polycyclic aromatic hydrocarbons [19]. It has been reported that metabolically activated benzo[a]pyrene induces cytotoxic, teratogenic, genotoxic, mutagenic, and carcinogenic effects in different types of mammalian cells and tissues [20].

\section{CONCLUSION}

Different breeds of rats (including Sprague Dawley, Long Evans and Wistar rats) and mice (balb $c$ and albino) have been used as leukaemia models using various chemical carcinogens including ENU, MNU, DMBA and $\mathrm{BaP}$.

The ages of rodents at the time of chemical inoculation range between a few days to several weeks. Five days to 3 weeks in mice as well as 4-8 weeks in rats. Mortality has been reported in younger mice due to acute toxicity of some of the chemicals. Male rodents are most studied, perhaps due to their resistance to toxic substances more than the female. However, it is recommended that female animals be also investigated to have a better understanding of the pathophysiology of the diseases in both sexes.

Various routes of administration (IP, IV and oral) have shown positive results in the animals studied. In mice, a total dose of 80 to $160 \mathrm{mg} / \mathrm{kg}$ body weight IP injection of ENU, given singly or in divided doses at certain intervals has shown to induced leukaemia 4-7 months after inoculation. In rats, however, a total of $225 \mathrm{mg} / \mathrm{kg}$ body weight IV injection of ENU in divided doses, 220 $\mathrm{mg} / \mathrm{kg}$ body weight IV injection of MNU in 6 divided doses and a total of $240 \mathrm{mg} / \mathrm{kg}$ body weight IP injection of MNU in 4 divided doses have been shown to induce leukaemia.

The leukaemia induced by these chemicals in rats and mice is characterised by enlargements of spleen, liver and lymph nodes, leukaemic blasts cells in both the bone marrow and peripheral blood smears, cells with round or oval 
nuclei and occasionally with indentations containing 1-3 nucleoli, among others.

These studies indicated that the different strains of mice and rats are susceptible to the early development of chemically-induced lymphoidhaematopoietic system (LHS) (pre)neoplasia. Consequently, these animal models appear to be suitable for use as a test system in bioassay protocols that adopt chemicals as initiating agents for carcinogenesis.

\section{COMPETING INTERESTS}

Authors have declared that no competing interests exist.

\section{REFERENCES}

1. Chang YC, Hsu JD, Lin WL, Lee YJ, Wang CJ. High incidence of acute promyelocytic leukemia specifically induced by $\mathrm{N}$-nitroso$\mathrm{N}$-methylurea ( NMU ) in Sprague Dawley rats. Arch Toxicol. 2012;86:31527.

2. DeSantis $C$, Siegel $R$, Bandi $P$, Jemal $A$. Breast cancer statistics, 2011. CA Cancer J Clin. 2011;61(6):409-18.

3. Boffetta P, Kaldor JM. Secondary malignancies following cancer chemotherapy. Acta Oncol. 1994;33(6):591-8.

4. Kohnken R, Porcu P, Mishra A. Overview of the use of murine models in leukemia and lymphoma research. Front Oncol [Internet]. 2017;7.

Available:http://journal.frontiersin.org/articl e/10.3389/fonc.2017.00022/full

5. Macejová D, Brtko J. Chemically induced carcinogenesis: A comparison of 1-methyl1-nitrosourea, 7,12-dimethylbenzanthracen e,diethylnitroso-amine and azoxymethan models (minireview). Endocr Regul. 2001; 35(1):53-9.

6. Boyonoski AC, Spronck JC, Gallacher LM, Jacobs RM, Shah GM, Poirier GG, et al. Niacin deficiency decreases bone marrow poly(ADP-ribose) and the latency of ethylnitrosourea-induced carcinogenesis in rats. J Nutr [Internet]. 2002;132(1):10814.

Available:http://www.ncbi.nlm.nih.gov/pub med/11773516

7. Gerson SL, Trey JE, Miller K, Berger NA. Comparison of O6-alkylguanine-DNA alkyltransferase activity based on cellular DNA content in human, rat and mouse tissues. Carcinogenesis. 1986;7(5):7459.

8. Lautier D, Lagueux J, Thibodeau J, Menard L, Poirier GG. Molecular and biochemical features of poly (ADP-ribose) metabolism. Mol Cell Biochem [Internet]. 1993;122(2):171-93.

Available:http://www.ncbi.nlm.nih.gov/entre z/query.fcgi?cmd=Retrieve\&db=PubMed\& dopt $=$ Citation\&list_uids $=8232248$

9. Le Rhun Y, Kirkland JB, Shah GM. Cellular responses to DNA damage in the absence of Poly(ADP-ribose) polymerase. Biochem Biophys Res Commun. 1998;245:1-10.

10. Zeller WJ, Schmähl D. Leukemias induced by ethylnitrosourea in Wistar rats: Incidence and chemotherapy. Leuk Res. 1979;3(4).

11. Law S, Maiti D, Palit A, Majumder D, Basu $\mathrm{K}$, Chaudhuri $\mathrm{S}$, et al. Facilitation of functional compartmentalization of bone marrow cells in leukemic mice by biological response modifiers: An immunotherapeutic approach. Immunol Lett. 2001;76(3):14552.

12. Bhattacharjee $B$, And AKS, Maiti D. Role of G-CSF plus IL-15 on neutrophil population in peripheral blood modulating protein tyrosine kinase activity in leukemic mouse Bhaskar Bhattacharjee, Ashish Kumar Singha and Debasish Maiti. Int J Curr Res. 2015;7(4):15180-6.

13. Singha AK, Bhattacharjee $B$, Saha B, Maiti D. IL-3 and GM-CSF modulate functions of splenic macrophages in ENU induced leukemia. Cytokine [Internet]. 2017;91:8995.

Available:http://dx.doi.org/10.1016/j.cyto.20 16.12.009

14. da Silva Franchi CA, Bacchi MM, Padovani $\mathrm{CR}$, de Camargo JL. Thymic lymphomas in Wistar rats exposed to. Cancer Sci. 2003; 94(3):4-7.

15. Hutheyfa AH, Hamzah H, SMR, Sabri J, Mohamed Mustapha NSS. Histopathological features of peripheral T-cell lymphoma in sprague dawley rats induced with N-methyl-N-nitrosourea. Pertanika J Trop Agric Sci [Internet]. 2011;34:35161.

Available:http://psasir.upm.edu.my/25342/

16. Elghetany MT, MacCallum JM, Davey FR. The use of cytochemical procedures in the diagnosis and management of acute and chronic myeloid leukemia. Clin Lab Med. 1990;10(4). 
17. Sugiyama $\mathrm{CBH}, \mathrm{T}$. Induction of leukaemia in rat by pulse doses. Pathology. 1965; 55:74-81.

18. Sugiyama T, Osaka M, Koami K, Maeda S, Ueda N. 7,12-DMBA-induced rat leukemia: A review with insights into future research. Leuk Res [Internet]. 2002;26(12):1053-68. [Cited 2017 May 5]

Available:http://ezproxy.upm.edu.my:2055/ science/article/pii/S0145212602000450
19. Shi Z, Dragin N, Miller ML, Stringer KF, Johansson E, Chen J, et al. Oral benzo[a]pyrene-induced cancer: Two distinct types in different target organs depend on the mouse Cyp1 genotype. Int J Cancer. 2010;127(10):2334-50.

20. Miller KP, Ramos KS. Impact of cellular metabolism on the biological effects of benzo[a]pyrene and related hydrocarbons. Drug Metab Rev. 2001;33(1):1-35.

(c) 2019 Aliyu et al.; This is an Open Access article distributed under the terms of the Creative Commons Attribution License (http://creativecommons.org/licenses/by/4.0), which permits unrestricted use, distribution, and reproduction in any medium, provided the original work is properly cited.

Peer-review history:

The peer review history for this paper can be accessed here: http://www.sdiarticle3.com/review-history/50887 